\title{
On the critical success factors for B2B e-marketplace
}

\author{
Sareh Ahmad Khan Beige and Farshid Abdi*
}

Department of Industrial Engineering, South Tehran Branch, Islamic Azad University, Tehran, Iran

\section{H R O N I C L E}

Article history:

Received March 15, 2014

Accepted September 6, 2014

Available online

September 82014

Keywords:

B2B EC

CSFs

Group ANP

\begin{abstract}
A B S T R A C T
Advancement of network technology, quick growth of Internet and Internet based solutions lead many firms to apply online processes as well as electronic businesses. Internet based B2B E-C requires applying Internet and affiliated technologies for exchanging products, services and information. Implementation of business to business (B2B) requires long-term commitment of organizations. Carrying out research in this field is regarded as very important issue for recognizing effective factors on successful implementation and execution of B2B and determining current status of organization. This research deals with studying effective critical factors on successful implementation and execution of B2B. Factors are recognized through studying literature review and IT experts. Then, through case study (studying a vehicle manufacturing firm) and by using analytical network process (ANP), the importance of factor and their rank are determined. The factors that are regarded at this research are including: culture, commitment and support of senior management, government support, purposes, organizational strategies, trust, partial advantage and technical infrastructure. Results of research show that support and commitment of senior management are the highest priority factors.
\end{abstract}

(C) 2015 Growing Science Ltd. All rights reserved.

\section{Introduction}

In recent decade with growth of electronic commerce (EC), the business is seriously influenced, so that technological and IT advancement effectively impact on today's economy and commerce. This event leads to using business to business B2B EC in recent decade and creating suitable grounds for economy. In fact, B2B EC is new form of organization created within digital environment. This type of commerce is defined between two or several businesses (often between business and suppliers) (Kaynak et al., 2005). B2B EC has some advantages including: reducing search cost, eliminating geographical impediments, facilitating transactions, finding more substitutes for products, comparing prices, etc. These advantages are regarded as important factor for encouraging organizations to apply for B2B electronic markets (Jianyuan \& Chunjuan, 2009). Any implementation of B2B EC is regarded as a system with high degree of problems including: complicacy, multiple relationships between trading firms. Therefore, implementation of this system requires having exact strategy and

* Corresponding author. Tel: +98 2177508894

E-mail address: farshidabdi@azad.ac.ir (F. Abdi) 
plan in all levels of organizations. At the present time, it seems that B2B EC is the most controversial discussions that attracted many researchers; nevertheless, this research has some problems such as: critical factors of a multidimensional concept that involves technical, individual, group and organizational level (Janom \& Zakaria, 2009; Hashemzadeh et al., 2014).

Although B2B EC has several advantages for organization, implementation and execution of this system is accompanied with numerous risks (Wang et al., 2012; Chang et al., 2012). Implementation of such commerce is time consuming process and its effect is determined on organizations in long term horizon. Making decision in relationship with the implementation and execution of B2B among many organizations is very difficult and it plays essential role on the success of organizations. Consequently, it is required to consider all aspects of implementation before reaching to inner organizational agreement (Wang \& Lin, 2009).

Successful implementation and execution of B2B EC raises some questions including: 1.What are critical factors of success/failure of B2B EC? 2. What is the level of importance of these factors on successful implementation and execution of B2B EC? According to purpose of this research, the first step is to recognize the most important factors of literature review and then rank a case study (vehicle manufacturing firm) through multiple criteria decision making (MCDM) technique called analytical network process (ANP).

Therefore, describing required factors for successful implementation of B2B is very important. Recognizing effective key factors on implementing B2B EC helps firms and organizations apply from required treatment activities to do certain successful implementation (Chang et al., 2012). The current evaluation studies and models of B2B EC are based on experiences of developed countries that are completely different with developing countries (Janom \& Zakaria, 2009). In this research, it is attempted to offer a model that is compatible with properties of Iran (as a developing country).

\section{Review on critical factors of success/failure of implementing B2B EC}

Upon studying literature review and interview with IT experts, the effective critical factors on success/failure of B2B EC are extracted.

\subsection{Commitment \& Support of Senior Management}

One of the effective key factor is commitment and support of senior management that many researches have proved this issue (Al-Somali et al., 2011; Thatcher et al., 2006; Chong et al., 2009; Zhai, 2010). Many literatures state that organizational innovation and management support is the most important effective factor on adopting innovation. Successful adoption of innovation requires support of senior management for integrating innovation of activities and business processes (AlSomali et al., 2011; Thatcher et al., 2006). Involvement of senior management has remarkable influence on successful implementation of B2B EC that strongly requires individual and managerial knowledge about B2B EC (Chong et al., 2009). A project that is supported by senior management is a project that is able to obtain enriched resources; since, senior managements are able to control remarkable and important resources; therefore, support of senior management directly influences on decision making (Zhai, 2010; Jianyuan et al., 2009).

\subsection{Purposes \& Strategies of Organization}

Purposes and strategies of organization is another effective factor on success/failure (Al-Somali et al., 2011; Al-Somali et al., 2011; Behkamal et al., 2006). Generally, successful utilization of information technology (IT) requires having strategic definition of IT and comprehensive management of ICT programs on complete and flexible basis (Al-Somali et al., 2011; Alirezaie \& Khosroshahi, 2014).

Strategic management literature focuses on strategic importance for assisting firms to obtain dynamic abilities within ever-changing environments (Al-Somali et al., 2011). Strategy for each firms using 
EC is important with respect to obtaining purposes and executing online transaction perspectives. Strategies of firms should be in compliance with recommendation values and chain value. In addition, strategy of a firm should refer to unique abilities of organization in order to obtain advantage in the field of EC. Good strategies of firm should be directed toward satisfaction of beneficiaries (Behkamal et al., 2006; Chen \& Chiu, 2014)

\subsection{Government Support}

Many literatures adopt that government support is necessary factor for adopting B2B EC (Thatcher et al., 2006; Chong et al., 2009; Zhai, 2010; Chong \& Ooi, 2008; Zhai, 2011; Nasri \& Charfeddine, 2012). Often government within developing countries controls development of technology and influences on decisions of implementing EC (Zhai, 2010; Zhai, 2011; Jianyuan \& Chunjuan, 2009). Different rates of implementation and execution of electronic systems in Asian countries are influenced by involvement of governments (Chong \& Ooi, 2008). Readiness of organization for using B2B EC depends on encouragement of government. Advertising activities, loans of government and preparing standards are regarded as important factors on success/failure of online commercial environments (Chong et al., 2009)

The nature of openness of Internet involves with many problems including: uncertainty, unsure, lack of security, absence of clarity, deceive and abuse of credit cards. Government support of EC and its regulations is regarded as important factor on introducing or adopting EC (Chong et al., 2009)

\subsection{Trust}

Many researches adopted that trust is the most important field that influences on success of B2B EC (Jianyuan \& Chunjuan, 2009; Chong et al., 2009; Zhai, 2010; Chong \& Ooi, 2008; Chong et al., 2012; Chong et al., 2009; Li et al., 2008). Trust is considered as preference of users for vulnerability and risk of using EC after considering its properties including: security, risk of personal domain and absence of face-to-face transactions (Chong et al., 2009).

Generally, absence of trust is regarded as impediment for successful execution of B2B EC (Chong et al., 2009). Trust consists of following items: sincerity, qualification, impartial, loyalty, freedom and clear information between commercial partners (Chong \& Ooi, 2008; Rezaei-Malek \& TavakkoliMoghaddam, 2014). There is a higher trust to electronic commerce than traditional commerce; since, online services and products are not approved immediately and there are few rules for preparing EC.

\subsection{Culture}

Culture is defined as common values for specific group of people or another definition is "group planning that refers to difference members of group from others". Anyway, national culture refers to image that most of people feel and their reaction toward a concept and subject (Thatcher et al., 2006). Customers have different values, attitudes, preferences of purchase; therefore, difference of national culture influences on consumer behavior with conditions of EC (Chong et al., 2009; Zhang et al., 2012). Many studies refer to culture as a critical factor for executing B2B EC (Thatcher et al., 2006; Chong et al., 2009; Zhang et al., 2012; Marasini et al., 2008).

For successful implementation of an organizational system, it is required for arranged implementation of this process between culture of employees and software procedures. At failure stage the implementation and execution of process is able to adapt components of inner organizational system with methods of performing work. Goodman and Green inferred that cultural and political factors are the main reason for absence of circulating IT at Middle East (Thatcher et al., 2006). Marasini et al. (2008) stated that electronic theft, lack of understanding system, complexity of system, reducing freedom and resistance are among effective indices on culture. 


\subsection{Relative Advantage}

Relative advantage is regarded as understanding advantages of innovation for improving competitive technologies. Many researchers showed that relative advantage of innovation has positive relationship with rate of adoption (Zhai, 2010; Li et al., 2008).The understood advantages refer to anticipated advantages that lead to having electronic market for organization. The most important advantages is reducing cost of transaction, reducing cost of search and eliminating geographical impediments (Li et al., 2008).

\subsection{Technical Infrastructures}

Technical infrastructures are regarded as key factor for executing B2B EC (Chong et al., 2009; Zhai, 2010; Jianyuan et al., 2009; Behkamal et al., 2006; Nasri et al., 2012). In order to apply from B2B $\mathrm{EC}$, the firms should benefit from basic infrastructure equipment including: computer, hardware, software, network and etc. Within short term only in case of having basic technical abilities the B2B EC plans may be successful (Zhai, 2010; Jianyuan et al., 2009). Appropriate infrastructures and high quality Internet influence on adoption behavior (Nasri et al., 2012).

Table 1 shows factors accompanied with studies. Upon determining indices and in compliance with mutual effects, the network structure is drawn. These factors are offered within TOE framework.

\section{Table 1}

Show factors accompanied with studies

\begin{tabular}{|c|c|}
\hline Culture & Chong et al., 2011; Wang et al., 2009; Zhang et al., 2012; Marasini et al., 2008; Ng, 2005 \\
\hline Technical infrastructure & $\begin{array}{l}\text { Jennex et al., 2004; Eid et al., 2004; Fu et al., 2006; Vaidya et al., 2006; Angeles \& Nath, 2007; } \\
\text { Kim \& Lee, } 2007\end{array}$ \\
\hline Support of senior management & $\begin{array}{l}\text { Thatcher et al., 2006; Fu et al., 2006; Vaidya et al., 2006; Janom et al., 2009; Cullen et } \\
\text { al., 2009; Zhai et al., 2011; Zhai \& Zhaofang, 2009; Eid \& Trueman, 2004; Solimana } \\
\text { et al., 2004 }\end{array}$ \\
\hline Government support & $\begin{array}{l}\text { Nasri et al., 2012; Looi et al., 2005; Jianyuan et al., 2009; Thatcher et al., 2006; Chong et al., } \\
\text { 2008; Son et al., 2007; Janom et al., 2009; Tan et al., 2007; Chong et al., 2011; Zakaria et al., } \\
\text { 2010 }\end{array}$ \\
\hline $\begin{array}{l}\text { Purposes and organizational } \\
\text { strategies }\end{array}$ & $\begin{array}{l}\text { Ng, 2005; Zakaria et al., 2009; Al-Somali et al., 2011; Eid \& Trueman, 2004; Javidian et al., } \\
\text { 2012; Li et al., 2005; }\end{array}$ \\
\hline Partial advantage & Looi, 2005; Alam et al., 2007; Jianyuan et al., 2007; Zhai et al., 2011; Solimana et al., 2004 \\
\hline Trust & $\begin{array}{l}\text { Chang et al., 2010; Marasini et al., 2008; Chong et al., 2009; Jianyuan et al., 2009; Alam et al., } \\
\text { 2007; Chong et al., 2012; Behkamal et al., 2006; Zhao et al., 2008; Eid et al., 2004; Zhai et al., } \\
\text { 2011; Solimana et al. 2004 }\end{array}$ \\
\hline
\end{tabular}

\section{Aims of Research}

This research benefits from structured decision making method for implementing and executing B2B EC. The result of this research is offering a framework for implementing and executing B2B EC. In short, these aims are including: 1. Recognizing effective key factors on B2B EC (through studying research background and interview with IT experts). 2. Offering model for anticipating success/failure of B2B EC. 3. Studying importance of factors on success/failure of B2B (ranking factors through case study).

\section{Research Methodology}

This research is regarded as applied research based on collecting information based on questionnaire.

\section{Method \& Tool of Data Collection}

Required information is divided into 2 classes including:

1. Recognizing key factors through library study, field study, interview with IT experts. 
2. Required information for testing model and ranking key factors on field study within questionnaire that was distributed among 25 managers and experts of vehicle manufacturing firm (4 senior managers and deputies, 3 experts from product engineering section, 5 experts from purchase section, 7 experts from planning section, 2 experts from strategic planning section and 4 experts from informatics section).

\section{Data Analysis Method}

Whereas recognized factors are not independent and have mutual influence and completing questionnaire by several managers, in this research it is applied from group ANP method.

\section{Review on ANP}

One of the most applicable methods on multi criterion decision making is ANP. This is extended method of analytic hierarchy process (AHP). Within AHP, the dependency is linear (i.e. from top to button and vice versa). Meanwhile, if dependency is bilateral i.e. weight of indices depends on choices and weight of choices is dependent to indices, the problem releases hierarchy from mode and forms a network or non-linear system that is not possible to apply rules and formula of AHP. In this case, in order to calculate weight of element, it is recommended to apply from ANP method. The ANP method is drawn for modeling network problem of available knots at this network that is equivalent to aims, factors and choices. Vectors connect these knots, which show effect of knots on each other. Fig. 1 shows difference between structure of network and hierarchy. In this figure, $\mathrm{W}_{21}$ is relative weight of factors in compliance with target knot and $W_{22}$ is inner weight of factors and $W_{23}$ is weight of choices in compliance with indices. After applying weights, the elementary super matrix is created. Then heterogeneous super matrix is created with normalization of columns for weight of super matrix or normalized. This matrix is on the power of $2 k+1$ for obtaining limit matrix. Limit matrix is a matrix that all numbers of row are equal to the final weight of that row. In this research the calculations is performed by Super Decision software.

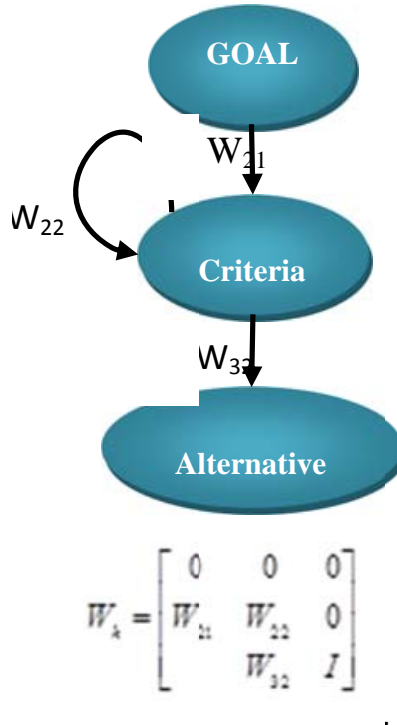

k

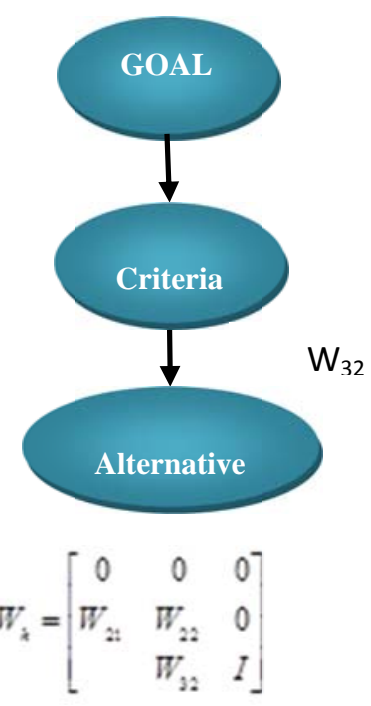

1y

Fig. 1. Structure of network and hierarchy

\section{Stages of Work}

\subsection{Producing Model and Turning Problem to a Network Structure}

At this stage, the desired problem is offered as network structure by having some knots as clusters (Fig. 2). 


\subsection{Formation of 2by2 Comparison Matrix and Determining Priority Vectors}

Similar to couple comparison at AHP, decision making elements for each cluster is compared based on their importance for relationship between 2 by 2 control factors. The cluster itself is compared based on role and effect for obtaining to purpose. The relative importance of elements such as AHP is assessed based on 9 scale quantity (Table 2).

Table 2

Comparing hierarchy analysis

\begin{tabular}{lll}
\hline Description & Definition & Degree of Importance \\
\hline Two elements have equal importance & Equal importance & 1 \\
One element is relatively more preferred than other element & Relatively preferred & 3 \\
One element is more preferred than other element & Highly preferred & 5 \\
One element is relatively more preferred than other element & Very high preferred & 7 \\
One element is extraordinary more preferred than other element & Extraordinary preferred & 9 \\
& Value for judgment & $2,4,6,8$ \\
\hline
\end{tabular}

In order to determine value of factors and sub-factors, it is recommended to prepare a questionnaire with 65 questions and submit it to 25 managers and experts of vehicle manufacturing firm. These people in compliance with their labor and organizational experience, determine relative importance of factors through couple (2by2) comparison. In order to merge comment of managers and experts, it is applied from geometrical average method and Excel software. Then obtained amounts are input at related matrixes of software and level of incompatibility is calculated. Authorized level of incompatibility of this research is 0.1 . If the level of incompatibility is higher than authorized level, in compliance with recommended priorities of software and through repeated referring to comment of experts, some of them are amended and then values are calculated. In this research the incompatibility level of matrixes is less than 0.1 .

\subsection{Formation of Super Matrix and Turning it Into Limit Super Matrix}

In this stage in compliance with completed matrixes at previous stage, the limit super matrix is calculated by using software

\subsection{Selecting Best Choice}

In this stage in compliance with available amounts at limit super matrix, importance and priority of factors and sub-factors is determined. Table 3 shows priority of main factors and table 4 shows priority of sub-factors.

Table 3

Priority of main factors

\begin{tabular}{cclc}
\hline Normalized & Limiting & Factors & Rank \\
\hline 0.29359 & 0.07402 & Management support and commitment & 1 \\
0.1753 & 0.044196 & Goals and strategies & 2 \\
0.16354 & 0.041232 & Government support & 3 \\
0.13261 & 0.033434 & Culture & 4 \\
0.08613 & 0.021714 & Technical infrastructure & 5 \\
0.0799 & 0.020144 & Trust & 6 \\
0.06893 & 0.017378 & Competitive advantage & 7 \\
\hline
\end{tabular}

Limiting column shows available amounts at limit matrix and Normalized column shows normal values. According to Table 3, support and commitment of senior management has the highest rank and lowest competitive advantage among main factors. 


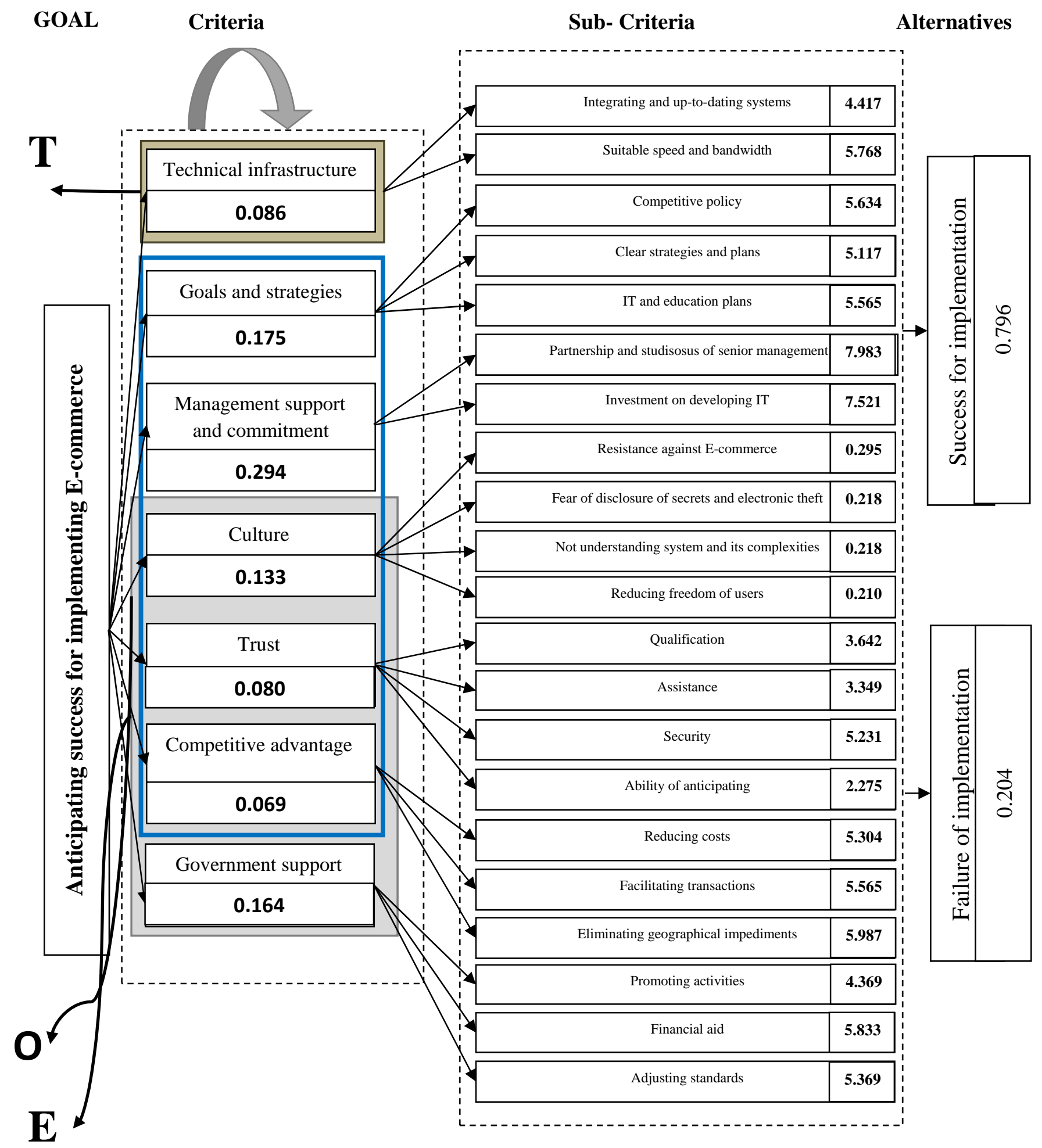

Fig. 2. Network structure and summary of values, factors, sub-factors and choices 
Table 4

Priority of sub-factors

\begin{tabular}{|c|c|c|c|c|}
\hline & Normalized & Limiting & Sub-factors & Rank \\
\hline \multirow[t]{2}{*}{ Technical infrastructure } & 0.56592 & 0.012289 & Suitable speed and bandwidth & 1 \\
\hline & 0.43408 & 0.009426 & Integrating and up-to-dating & 2 \\
\hline \multirow{4}{*}{ Culture } & 0.31431 & 0.010509 & Reducing freedom of users & 1 \\
\hline & 0.27591 & 0.009225 & Not understanding system and its & 2 \\
\hline & 0.24794 & 0.00829 & Fear of disclosure of secrets and & 3 \\
\hline & 0.16184 & 0.005411 & Resistance against & 4 \\
\hline \multirow{4}{*}{ Trust } & 0.49211 & 0.009913 & Security & 1 \\
\hline & 0.23079 & 0.004649 & Qualification & 2 \\
\hline & 0.14386 & 0.002898 & Ability of anticipating & 3 \\
\hline & 0.13324 & 0.002684 & Assistance & 4 \\
\hline \multirow{3}{*}{ Government support } & 0.4417 & 0.018212 & Financial aid & 1 \\
\hline & 0.34706 & 0.01431 & Adjusting standards & 2 \\
\hline & 0.21124 & 0.00871 & Promoting activities & 3 \\
\hline \multirow{2}{*}{$\begin{array}{l}\text { Management support and } \\
\text { commitment }\end{array}$} & 0.58386 & 0.043217 & Partnership and studisosus of & 1 \\
\hline & 0.41614 & 0.030803 & Investment on developing IT & 2 \\
\hline \multirow{3}{*}{ Competitive advantage } & 0.50941 & 0.008853 & Reducing costs & 1 \\
\hline & 0.24679 & 0.004289 & Eliminating geographical & 2 \\
\hline & 0.2438 & 0.004237 & Facilitating transactions & 3 \\
\hline \multirow{3}{*}{ Goals and strategies } & 0.41393 & 0.018294 & Competitive policy & 1 \\
\hline & 0.33467 & 0.014791 & Clear strategies and plans & 2 \\
\hline & 0.2514 & 0.011111 & IT and education plans & 3 \\
\hline
\end{tabular}

The sub-factor of partnership and studious senior management has the highest rank and assistance has the lowest rank among sub-factors. Finally, according to Fig. 2, ranking probable results of implementation and execution of B2B EC among vehicle manufacturing firms is: Success (0.7956) > failure (0.2044).

Evaluators believe that in compliance with limitations of organization, it is successful performance.

\section{Conclusion}

In this article, we have attempted to classify critical factors of success/failure for implementation of B2BEC. By reviewing the literature and some IT experts' comments, we have introduced a new method for ranking the factors in compliance with mutual relationship between factors. According to comments of 25 experts of vehicle manufacturing firms, some factors were recognized, evaluated and prioritized. Results of analysis have shown that support and commitment of senior management maintained the highest priority among some main factors. Priority of main factors has been reported as: 1. Support and commitment of senior management (0.2936), 2. Purposes and strategies of organization (0.1753), 3. Government support (0.1635), 4. Culture (0.1326), 5. Technical infrastructures (0.0861), 6. Trust (0.0799), 7. Competitive advantage (0.0689).

Finally, results of research show that vehicle manufacturing firms have successful performance in the field of benefiting from B2B EC system (success (0.7956)>failure (0.2044).

\section{References}

Al-Somali, S. A., Gholami, R., \& Clegg, B. (2011). Determinants of B2B e-commerce adoption in Saudi Arabian firms. International Journal of Digital Society (IJDS), 2(2), 406-415.

Alam, S. S., Khatibi, A., Ahmad, M. I. S., \& Ismail, H. B. (2008). Factors affecting e-commerce adoption in the electronic manufacturing companies in Malaysia. International Journal of Commerce and Management, 17(1/2), 125-139.

Alirezaie, A \& Khosroshahi, S. (2014). Which contractor selection methodology?. Uncertain Supply Chain Management, 2(4), 257-260.

Angeles, R., \& Nath, R. (2007). Business-to-business e-procurement: success factors and challenges to implementation. Supply Chain Management: An International Journal, 12(2), 104-115. 
Chang, H. H., \& Wong, K. H. (2010). Adoption of e-procurement and participation of e-marketplace on firm performance: Trust as a moderator. Information \& Management, 47(5), 262-270.

Chang, T. H., Hsu, S. C., Wang, T. C., \& Wu, C. Y. (2012). Measuring the success possibility of implementing ERP by utilizing the Incomplete Linguistic Preference Relations. Applied Soft Computing, 12(5), 1582-1591.

Chen, Y \& Chiu, Y. (2014). Enhancing business intelligence for supply chain operations through effective classification of supplier management. Uncertain Supply Chain Management, 2(4), 229236.

Chong, A. Y. L., \& Ooi, K. B. (2008). Adoption of interorganizational system standards in supply chains: an empirical analysis of RosettaNet standards. Industrial Management \& Data Systems, 108(4), 529-547.

Chong, A. Y. L., Ooi, K. B., Lin, B., \& Tang, S. Y. (2009). Influence of interorganizational relationships on SMEs'e-business adoption. Internet Research, 19(3), 313-331.

Chong, W. K., Shafaghi, M., \& Tan, B. L. (2011). Development of a business-to-business critical success factors (B2B CSFs) framework for Chinese SMEs. Marketing Intelligence \& Planning, 29(5), 517-533.

Chong, A. Y. L., Chan, F. T., \& Ooi, K. B. (2012). Predicting consumer decisions to adopt mobile commerce: Cross country empirical examination between China and Malaysia. Decision Support Systems, 53(1), 34-43.

Cullen, A. J., \& Taylor, M. (2009). Critical success factors for B2B e-commerce use within the UK NHS pharmaceutical supply chain. International Journal of Operations \& Production Management, 29(11), 1156-1185.

Eid, R., \& Trueman, M. (2004). Factors affecting the success of business-to-business international internet marketing (B-to-B IIM): an empirical study of UK companies. Industrial Management \& Data Systems, 104(1), 16-30.

Fu, H. P., Ho, Y. C., Chen, R. C., Chang, T. H., \& Chien, P. H. (2006). Factors affecting the adoption of electronic marketplaces: a fuzzy AHP analysis. International Journal of Operations \& Production Management, 26(12), 1301-1324.

Hashemzadeh, G., Modiri, M \& Rahimi, Z. (2014). Identification and ranking effective factors on establishment of green supply chain management in railway industry. Uncertain Supply Chain Management, 2(4), 293-302.

Janom, N., \& Zakaria, M. S. (2009, August). B2B e-commerce readiness assessment indicators based on the critical success factors. In Electrical Engineering and Informatics, 2009. ICEEI'09. International Conference on (Vol. 2, pp. 405-411). IEEE.

Jennex, M. E., Amoroso, D., \& Adelakun, O. (2004). E-commerce infrastructure success factors for small companies in developing economies. Electronic Commerce Research, 4(3), 263-286.

Jianyuan, Y., \& Chunjuan, Z. (2009, September). An empirical study on influence factors for organizations to adopt B2B e-marketplace in China. Management and Service Science, 2009. MASS'09. International Conference on(pp. 1-6). IEEE.

Kaynak, E., Tatoglu, E., \& Kula, V. (2005). An analysis of the factors affecting the adoption of electronic commerce by SMEs: Evidence from an emerging market. International Marketing Review, 22(6), 623-640.

Lee, S., \& Kim, K. J. (2007). Factors affecting the implementation success of Internet-based information systems. Computers in Human Behavior, 23(4), 1853-1880.

Li, J., \& Li, L. (2005, August). On the critical success factors for B2B e-marketplace. In Proceedings of the 7th international conference on Electronic commerce (pp. 119-122). ACM.

Li, Y., Wang, W., Zhu, Y., \& Chen, J. (2008, September). A Unified Model of B2B E-Marketplace Adoption: Integrating the Transactional and Relational Perspectives. In Advanced Management of Information for Globalized Enterprises, 2008. AMIGE 2008. IEEE Symposium on (pp. 1-5). IEEE.

Looi, H. C. (2005). E-commerce adoption in Brunei Darussalam: a quantitative analysis of factors influencing its adoption. Communications of the Association for Information Systems, 15(1), 3. 
Marasini, R., Ions, K., \& Ahmad, M. (2008). Assessment of e-business adoption in SMEs: A study of manufacturing industry in the UK North East region. Journal of Manufacturing Technology Management, 19(5), 627-644.

Ng, E. (2005). An empirical framework developed for selecting B2B e-business models: the case of Australian agribusiness firms. Journal of Business \& Industrial Marketing, 20(4/5), 218-225.

Nasri, W., \& Charfeddine, L. (2012). Factors affecting the adoption of Internet banking in Tunisia: An integration theory of acceptance model and theory of planned behavior. The Journal of High Technology Management Research,23(1), 1-14.

Rezaei-Malek, M \& Tavakkoli-Moghaddam, R. (2014). Robust humanitarian relief logistics network planning. Uncertain Supply Chain Management, 2(2), 73-96.

Soliman, K. S., \& Janz, B. D. (2004). An exploratory study to identify the critical factors affecting the decision to establish Internet-based interorganizational information systems. Information \& Management, 41(6), 697-706.

Son, J. Y., \& Benbasat, I. (2007). Organizational buyers' adoption and use of B2B electronic marketplaces: efficiency-and legitimacy-oriented perspectives. Journal of Management Information Systems, 24(1), 55-99.

Tan, J., Tyler, K., \& Manica, A. (2007). Business-to-business adoption of eCommerce in China. Information \& management, 44(3), 332-351.

Thatcher, S., Foster, W., \& Zhu, L. (2006). B2B e-commerce adoption decisions in Taiwan: The interaction of cultural and other institutional factors. Electronic Commerce Research and Applications, 5(2), 92-104.

Vaidya, K., Sajeev, A. S. M., \& Callender, G. (2006). Critical factors that influence e-procurement implementation success in the public sector. Journal of public procurement, 6(1/2), 70.

Wang, T. C., \& Lin, Y. L. (2009). Accurately predicting the success of B2B e-commerce in small and medium enterprises. Expert Systems with Applications,36(2), 2750-2758.

Wang, S., Mao, J. Y., \& Archer, N. (2012). On the performance of B2B e-markets: An analysis of organizational capabilities and market opportunities. Electronic Commerce Research and Applications, 11(1), 59-74.

Yu, C. S. (2007). What drives enterprises to trading via B2B e-marketplaces?. Journal of Electronic Commerce Research, 8(1), 84-100.

Zhai, C. (2010, August). Research on Post-Adoption Behavior of B2B E-Marketplace in China. In Management and Service Science (MASS), 2010 International Conference on (pp. 1-5). IEEE.

Zhai, C. (2011, June). Study on environment factors affecting B2B e-marketplace adoption in China: From e-readiness perspective. In Computer Science and Service System (CSSS), 2011 International Conference on (pp. 4062-4065). IEEE.

Zhang, Y., Deng, X., Wei, D., \& Deng, Y. (2012). Assessment of E-Commerce security using AHP and evidential reasoning. Expert Systems with Applications,39(3), 3611-3623.

Zhao, J., Wang, S., \& Huang, W. V. (2008). A study of B2B e-market in China: E-commerce process perspective. Information \& Management, 45(4), 242-248. 